\title{
Effect of local anesthesia (with lidocaine vs bupivacaine) on cognitive function in patients undergoing elective cataract surgery
}

This article was published in the following Dove Medical Press journal: Local and Regional Anesthesia

\author{
Wael Fathy' \\ Mona Hussein ${ }^{2}$ \\ Hossam Khalil ${ }^{3}$ \\ 'Department of Anaesthesia, Beni- \\ suef University, Beni Suef, Egypt; \\ ${ }^{2}$ Department of Neurology, Beni- \\ suef University, Beni Suef, Egypt; \\ ${ }^{3}$ Department of Ophthalmology, Beni- \\ suef University, Beni Suef, Egypt
}

Purpose: Postoperative cognitive dysfunction has gained much attention over the last years. Multiple clinical trials have attempted to differentiate the effect of local vs general anesthesia on postoperative cognitive function. The aim of this work was to study the effect of local anesthesia with lidocaine vs bupivacaine on cognitive function

Patients and methods: This was a prospective randomized trial carried out on 61 patients undergoing elective cataract surgery by phacoemulsification under local anesthesia. Twenty-eight patients received lidocaine $2 \%$ and 33 patients received bupivacaine $0.5 \%$. Cognitive assessment for all patients was done preoperatively and 1 week postoperatively using paired associate learning test (PALT) and category verbal fluency (VF) test (animal category).

Results: Regarding cognitive assessment of patients in lidocaine group, there was a statistically significant difference between the mean value of preoperative PALT and postoperative PALT $(P$-value $=0.004)$, and between the mean value of preoperative VF and postoperative VF $(P$-value $=0.002$ ). As for bupivacaine group, there was a statistically significant difference between the mean value of preoperative PALT and postoperative PALT $(P$-value $=0.021)$, and between the mean value of preoperative VF and postoperative VF $(P$-value $=0.037)$. On comparing lidocaine and bupivacaine groups in pre and postoperative PALT \& VF scores, there was no statistically significant difference between both groups

Conclusion: Both lidocaine and bupivacaine caused postoperative cognitive impairment. Lidocaine was found to have a worse effect on cognitive function than bupivacaine, but the difference was not statistically significant.

Keywords: lidocaine, bupivacaine, cataract, PALT, VF

\section{Introduction}

Much concern has been raised about the effects of anesthetic drugs on cognition. The proportion of postoperative cognitive dysfunction (POCD) after surgery is as high as $10 \%-62 \%$, which seriously affects the quality of life of patients. ${ }^{1}$ POCD may manifest as impairment in attention, memory, language or executive functions following surgery, and can persist for weeks, months, or longer with varying severity. POCD can be mild and only diagnosed by psychometric assessment using specific neuropsychological tests. ${ }^{2}$ Postoperatively, patients may experience some difficulty in resuming their normal activities, forget appointments, names, and phone numbers, and discover problems in recalling recent events. Such deterioration in cognitive function may have serious consequences on the patient's ability to work. ${ }^{3}$

Multiple clinical trials have attempted to differentiate the effect of general vs regional anesthesia on cognitive function. While most of the studies showed no
Correspondence: Mona Hussein Department of Neurology, Beni-suef University, Salah Salem Street, Beni Suef $625 \mathrm{II}$, Egypt

Tel +200100513 1318

Email mona.neuro@yahoo.com 
difference in postoperative cognitive function between regional and general anesthesia, some trials showed a significant difference in postoperative cognitive outcomes between the two anesthetic techniques..$^{4-8}$

The pathogenesis of cognitive dysfunction following local anesthesia can be attributed to its neurotoxic side effects. Local anesthetics are known to be neurotoxic in a dose-dependent manner. However, it has to be noted that the exact pathway of cell death depends on the concentration of local anesthetic. For example, in Jurkat cells (immortalized lymphocytes), clinically relevant concentrations of lidocaine induced apoptosis, while higher concentrations induced necrosis and unspecific cell death. ${ }^{9,10}$

There is a large amount of evidence that the toxicity among local anesthetics varies. This evidence suggests that lidocaine is more toxic than equipotent concentrations of bupivacaine. ${ }^{11,12}$ However, this is still up for debate as other studies have shown that there is no difference in toxicity between local anesthetics. ${ }^{13}$

The aim of this work was to study the effect of local anesthesia with lidocaine vs bupivacaine on cognitive function.

\section{Patients and methods}

\section{Study design and population}

This was a prospective randomized trial carried out on 61 patients undergoing elective cataract surgery. Patients were randomly assigned to one of two groups; the first group received local anesthesia with lidocaine $2 \%$ and the second group received local anesthesia with bupivacaine $0.5 \%$. Randomization was carried out using a closed opaque envelope technique where the anesthetist picked up a sealed envelope which contained a sheet of paper with the name of the group to which the patient had been randomized. The patient was scheduled to whichever group was written on the paper. The patients were recruited during the period between June 2018 and August 2018 from the Ophthalmology outpatient clinics of Beni-suef University Hospital.

\section{Inclusion criteria}

Out of 61 patients undergoing elective cataract surgery by phacoemulsification under local anesthesia, 28 patients received lidocaine $2 \%$ and 33 patients received bupivacaine $0.5 \%$. The subjects provided signed, written informed consent to participate and if cataract markedly affected the vision of the patient, written informed consent was obtained from a family member. The study was approved by the local ethics committee of Faculty of Medicine, Beni-suef University. The study was conducted in accordance with the
Declaration of Helsinki. The study was registered in the Pan African Clinical Trial Registry with identification number PACTR201806003395974.

\section{Exclusion criteria}

Exclusion criteria: patients with major language disturbance or auditory impairment affecting their ability to complete testing, patients with preexisting cognitive, psychiatric or central nervous system disorders, patients with nystagmus, allergy to local anesthetics, intravenous sedation, any coexisting ocular conditions that could affect the scoring system for local anesthesia such as ptosis, ocular movement abnormality, reduced corneal sensation, or facial nerve palsy, inability to understand the information about the study or if the patient refused the local anesthesia technique.

\section{All patients included in the study were subjected to the following}

1) Cognitive assessment: cognitive assessment for all patients was done preoperatively and 1 week postoperatively using paired associate learning test (PALT) and category verbal fluency (VF) test (animal category). PALT is used to assess verbal memory. In this test, the examiner lists ten associated pairs in front of the candidate. These pairs contain six compatible semantically related pairs and four incompatible semantically unrelated pairs. After 1 minute, the candidate is given the first word of the pairs and is asked to recall the second word. The test is repeated three times. Each correct compatible pair has a score of 0.5 , while each correct incompatible pair has a score of 1 . The total score ranges from 0 to $21 .{ }^{14}$ Category VF test is used to assess attention and executive function. In this test, the patient is asked to name as many animals as possible within 1 minute. Each animal he names, has a score of $1 .^{15}$

2) Anesthetic technique: anesthesia during cataract surgery was performed for all patients by the same anesthesiologist using the same anesthetic technique. The included 61 patients in the study were divided into two groups; the first group included 28 patients injected with lidocaine $2 \%$ with total volume $7 \mathrm{~mL}$ and the second group included 33 patients injected with bupivacaine $0.5 \%$ with the same volume, $7 \mathrm{~mL}$, hyaluronidase $15 \mathrm{IU}$ was added to the drugs before injection, all patients were allocated using random number tables. All patients were guided to the preparation room, venous access was obtained using antiseptic technique, standard monitoring was applied (electrocardiogram, oxygen saturation, non-invasive blood pressure), no premedication was given to the 
patients, only psychological reassurance, amethocaine eye drops were instilled to provide topical anesthesia to all patients. Blocks were performed by one anesthetist. In all cases, a peribulbar injection technique was used with a $25 \mathrm{~mm} 25 \mathrm{G}$ needle using complete antiseptic technique, patients were injected with a volume of $4 \mathrm{~mL}$ inferolaterally after negative aspiration with the patients looking straight ahead and $3 \mathrm{~mL}$ through the medial canthus. A total of $7 \mathrm{~mL}$ of local anesthetic solution was injected in all patients. The inferolateral injection was performed before the medial canthal injection. Digital pressure was applied for 5 minutes which was released every 30 seconds for 5 seconds. The quality of the block was assessed every 2 minutes by an observer rather than the anesthetist blinded to the drugs. The motor functions (levator, orbicularis oculi and the extraocular muscles; up, down, medial, lateral) and sensory functions (digital spear pressure at limbus and topical anesthetic sting) were evaluated using Ocular Anaesthetic Scoring System (OASS). ${ }^{16}$ Intraoperative pain was assessed using the visual analogue pain (VAP) scale. ${ }^{17}$

3) Surgical technique: cataract surgery was performed for all patients by the same surgeon using the same surgical technique. Surgery was performed after prior conjunctival and periocular cleansing with povidone iodine $5 \%$ and $10 \%$ solution, respectively. In all patients, a $2.8 \mathrm{~mm}$ clear corneal incision was made at the most curved axis. Phacoemulsification was performed with implantation of an acrylic intraocular lens into the capsular bag through a sutureless incision.

\section{Statistical methods}

The sample size calculation was done using $G^{*}$ Power version 3.1.9.2 Software based on our pretrial pilot study. The probability of type I error $(\alpha)$ was $5 \%$, and the power $(1-\beta)$ was $90 \%$. A total of 61 participants were required for statistical significance. The data were coded and entered using SPSS version 18. Descriptive statistics were reported as mean \pm SD and number ( $\%$ ) for categorical variables. Student's $t$-test was used for comparison between means of two unpaired groups of quantitative variables. Paired sample $t$-test was used for comparison between means of two paired groups of quantitative variables. Chi-squared test was used for comparison between two groups of categorical data. Mixed ANOVA test was used for comparing paired data in two unpaired groups. The probability/significance value $(P$-value $) \geq 0.05$ was not statistically significant and $<0.05$ was statistically significant.

\section{Results}

The mean age of patients in lidocaine group $(n=28)$ was $51.29 \pm 11.42$ years, while the mean age of patients in bupivacaine group $(n=33)$ was $55.97 \pm 11.35$ years. In lidocaine group, $46.4 \%(n=13)$ of the patients were males and $53.6 \%$ $(n=15)$ were females. Regarding patients in bupivacaine group, $33.3 \%(n=11)$ were males and $66.7 \%(n=22)$ were females. There was no statistically significant difference between both groups in either age $(P$-value $=0.11)$ or sex $(P$-value $=0.297)($ Table 1$)$.

Regarding motor score of OASS, patients in lidocaine group were found to have significantly higher mean values in the total motor score than patients in bupivacaine group ( $P$-value $<0.001)$, while there was no statistically significant difference between patients in lidocaine group and those in bupivacaine group in the total sensory score of OASS $(P$-value $=0.168)$ or VAP scale score $(P$-value $=0.787)$ (Table 2).

Regarding the total score of PALT in patients in lidocaine group, there was a statistically significant difference between the mean value of preoperative PALT (11.29 \pm 4.77$)$ and postoperative PALT $(10.27 \pm 5.63)(P$-value $=0.004)$. In bupivacaine group, there was a less statistically significant difference between the mean value of preoperative PALT $(10.29 \pm 5.05)$ and postoperative PALT $(9.82 \pm 4.96)(P$-value $=0.021$ ). On comparing lidocaine and bupivacaine groups in pre and postoperative PALT scores, there was no statistically significant difference between both groups ( $P$-value $=0.579)$ (Table 3 ).

Regarding the total score of VF in patients in lidocaine group, there was a statistically significant difference between the mean value of preoperative VF $(9.57 \pm 2.24)$ and postoperative VF $(8.54 \pm 1.43)$ ( $P$-value $=0.002)$. In bupivacaine group, there was a less statistically significant difference between the mean value of preoperative VF $(9.06 \pm 2.46)$ and postoperative VF $(8.58 \pm 2.02)(P$-value $=0.037)$. On comparing lidocaine and bupivacaine groups regarding pre and

Table I Demographics of patients in lidocaine and bupivacaine groups

\begin{tabular}{|c|c|c|c|c|}
\hline \multicolumn{2}{|c|}{ Demographics } & $\begin{array}{l}\text { Lidocaine } \\
\text { group }(n=28)\end{array}$ & $\begin{array}{l}\text { Bupivacaine } \\
\text { group }(n=33)\end{array}$ & $P$-value \\
\hline \multicolumn{2}{|c|}{$\begin{array}{l}\text { Age in years } \\
\text { [mean SD] }\end{array}$} & 51.29 (II.42) & 55.97 (11.35) & 0.11 \\
\hline \multirow[t]{2}{*}{ Sex } & Male [n (\%)] & $13(46.4 \%)$ & $\mathrm{II}(33.3 \%)$ & \multirow[t]{2}{*}{0.297} \\
\hline & Female [n (\%)] & $15(53.6 \%)$ & $22(66.7 \%)$ & \\
\hline
\end{tabular}

Note: $P$-value $\geq 0.05$ (non-significant). 
postoperative VF scores, there was no statistically significant difference between both groups $(P$-value $=0.642)$ (Table 4$)$.

\section{Discussion}

POCD has gained much attention over the last years. Multiple clinical trials have attempted to differentiate the effect of regional vs general anesthesia on postoperative cognitive function. Nevertheless, the importance of postoperative cognitive decline has long been debated. Descriptions such as "transient", "subtle", and "subclinical" have been used to minimize the importance of these changes to clinicians, patients, and their families. POCD was thought to be a reversible condition in the majority of elderly patients undergoing surgery. However, a significant positive correlation between postoperative cognitive decline and long-term cognitive dysfunction was recently demonstrated. ${ }^{18}$ Such correlation suggests that POCD may serve either as a marker of brain injury, increased susceptibility to brain injury, decreased reserve capacity, or inability to recover or tolerate similar injury (plasticity). ${ }^{19}$

A systematic review was done by Davis et $a^{8}$ to compare the risk of POCD following general vs regional anesthesia. Sixteen studies met inclusion criteria and were included in the final analysis. The investigators found that only 3 studies showed some differences in postoperative cognitive function between regional and general anesthesia, while the remaining 13 showed no differences between regional and general anesthesia.

The variability of the results of various studies could largely be attributed to the absence of a standard POCD definition, the disparity in targeted population, the heterogeneity of procedures used to measure cognitive deficits, and the different methods used for statistical analysis. In addition, the complex interaction of the potential confounders can make it difficult to isolate the influence of anesthesia itself. ${ }^{20,21}$

Table 2 Assessment of motor functions, sensory function, and intraoperative pain in lidocaine vs bupivacaine group

\begin{tabular}{|c|c|c|c|c|}
\hline \multicolumn{2}{|c|}{$\begin{array}{l}\text { Ocular anaesthetic scoring system and intraoperative } \\
\text { pain }\end{array}$} & \multirow{2}{*}{$\begin{array}{l}\text { Lidocaine group } \\
(n=28)\end{array}$} & \multirow{2}{*}{$\begin{array}{l}\text { Bupivacaine group } \\
(\mathbf{n}=\mathbf{3 3})\end{array}$} & \multirow{2}{*}{$\begin{array}{l}P \text {-value } \\
<0.00 \text { I* }^{*}\end{array}$} \\
\hline Motor function & Levator (0-2) & & & \\
\hline [mean SD] & Orbicularis oculi (0-2) & 0.75 & 0.33 & $0.003 *$ \\
\hline & EOM-up (0-2) & 0.5 & 0.30 & 0.154 \\
\hline & EOM-down (0-2) & 0.36 & 0.42 & 0.6 \\
\hline & EOM-lateral (0-2) & 0.54 & 0.30 & 0.07 \\
\hline & EOM-medial (0-2) & 0.39 & 0.24 & 0.218 \\
\hline & Total motor $(0-12)$ & 3.39 & 1.94 & $<0.00 I^{*}$ \\
\hline \multirow{3}{*}{$\begin{array}{l}\text { Sensory function } \\
\text { [mean SD] }\end{array}$} & Digital spear pressure $(0-1)$ & 0.21 & 0.15 & 0.533 \\
\hline & Topical anesthetic sting $(0-1)$ & 0.11 & 0.00 & 0.083 \\
\hline & Total sensory (0-2) & 0.32 & 0.15 & 0.168 \\
\hline Pain [mean SD] & VAP scale $(0-10)$ & 0.07 & 0.09 & 0.787 \\
\hline
\end{tabular}

Notes: $P$-value $\geq 0.05$ (non-significant), ${ }^{*} P$-value $<0.05$ (significant).

Abbreviations: EOM, extraocular muscles; VAP, visual analogue pain.

Table 3 Pre and postoperative PALT scores in lidocaine vs bupivacaine group

\begin{tabular}{|l|l|l|l|l|l|}
\hline \multicolumn{2}{|l|}{ Cognitive assessment } & $\begin{array}{l}\text { Preoperative } \\
\text { assessment }\end{array}$ & $\begin{array}{l}\text { Postoperative } \\
\text { assessment }\end{array}$ & P-value & $\begin{array}{l}\text { P-value between } \\
\text { groups }\end{array}$ \\
\hline $\begin{array}{l}\text { PALT } \\
{[\text { mean SD] }}\end{array}$ & Lidocaine group & $11.29(4.77)$ & $10.27(5.63)$ & $0.004^{*}$ & 0.579 \\
\cline { 2 - 5 } & Bupivacaine group & $10.29(5.05)$ & $9.82(4.96)$ & $0.021^{*}$ & \\
\hline
\end{tabular}

Note: $* P$-value $<0.05$ (significant).

Abbreviation: PALT, paired associate learning test.

Table 4 Pre and postoperative VF scores in lidocaine vs bupivacaine group

\begin{tabular}{|l|l|l|l|l|l|}
\hline \multicolumn{2}{|l|}{ Cognitive assessment } & $\begin{array}{l}\text { Preoperative } \\
\text { assessment }\end{array}$ & $\begin{array}{l}\text { Postoperative } \\
\text { assessment }\end{array}$ & P-value & $\begin{array}{l}\text { P-value } \\
\text { between groups }\end{array}$ \\
\hline \multirow{2}{*}{ VF [mean SD] } & Lidocaine group & $9.57(2.24)$ & $8.54(1.43)$ & $0.002^{*}$ & 0.642 \\
\cline { 2 - 5 } & Bupivacaine group & $9.06(2.46)$ & $8.58(2.02)$ & $0.037^{*}$ & \\
\hline
\end{tabular}

Note: $* P$-value $<0.05$ (significant).

Abbreviation: VF, verbal fluency. 
Although many studies were done to compare the risk of POCD following general vs local anesthesia, no comparative studies have been done to investigate the effect of various local anesthetics on cognitive function. Our study aimed at determining which of the two local anesthetic drugs (lidocaine vs bupivacaine) had a worse effect on cognitive function in patients undergoing elective cataract surgery. Our results revealed that both lidocaine and bupivacaine caused POCD in verbal memory, attention, and executive function. Lidocaine was found to be worse than bupivacaine but the difference was not statistically significant.

Our findings can be explained by the neurotoxic effect of local anesthetics. Local anesthetics are known to induce apoptosis, unspecific cell death, and necrosis. There are possible mechanisms that cause apoptosis in neurons. Local anesthetics can lead to fragmentation of DNA and disruption of the membrane potential in mitochondria. This results in the uncoupling of the oxidative phosphorylation, which subsequently causes the release of cytochrome $c$ and the initiation of the caspase pathway leading to apoptosis. ${ }^{9}, 10$

The reported postoperative cognitive decline in the present study can be attributed to the combined effect of surgery and local anesthesia. So, further studies are needed to clarify the effect of surgery alone on cognitive function.

The main limitation of this work was the lack of measurement of markers of neuronal degeneration that could help to compare the intensity of neurotoxicity between the two anesthetic drugs. Further studies should be conducted on a larger number of patients and for a longer duration to clarify if POCD following local anesthesia is reversible or not. Additionally, the effect of surgery alone on cognitive function should be tested. Closer observation of oculomotor function following local anesthesia for a longer period should be done.

\section{Conclusion}

Both lidocaine and bupivacaine caused postoperative impairment in verbal memory, attention, and executive function due to their neurotoxic side effects. Lidocaine was found to be worse than bupivacaine but the difference was not statistically significant. Lidocaine significantly affected motor function compared to bupivacaine in patients undergoing elective cataract surgery.

\section{Ethics approval and consent to participate}

The study was conducted in accordance with the Declaration of Helsinki. Written informed consent was obtained from each participant in this study or from a family member (if cataract markedly affected the vision of the patient) and the study was approved by the local ethics committee of Faculty of medicine, Beni-suef University.

\section{Acknowledgements}

The authors did not receive any funding for this work. The abstract of this paper was presented at Euroanaesthesia congress 2018 (Copenhagen, Denmark, 2-4 June 2018) at Bella Center as a poster presentation. The session date was 3 June 2018, and the session time was 10:15-11:45. The poster's abstract was published in "Poster Abstracts" in the e-Supplement of the European Journal of Anaesthesiology (Volume 35, Supplement 56).

\section{Author contributions}

WF participated in study conception and design, sequence alignment, and helped to draft the manuscript. HK participated in collection and analysis of data and helped to draft the manuscript. MH participated in collection of data, data analysis, and helped to draft the manuscript. All authors contributed to data analysis, drafting or revising the article, gave final approval of the version to be published, and agree to be accountable for all aspects of the work.

\section{Disclosure}

The authors report no conflicts of interest in this work.

\section{Data sharing statement}

The authors report that the data supporting their findings can be found and can be publicly shared. The authors intend to share the data regarding patient demographics and pre and postoperative cognitive assessment. Patients' consent, ethics committee approval, and cognitive tests will be available. The data can be accessed by contacting the corresponding author (email is available). The data will be made available for 1 year after publication in Local and Regional Anesthesia journal.

\section{References}

1. Vatter H, Konczalla J, Seifert V. Endothelin related pathophysiology in cerebral vasospasm: what happens to the cerebral vessels? Acta Neurochir Suppl. 2011;110:177-180.

2. Steinmetz J, Christensen KB, Lund T, Lohse N, Rasmussen LS; ISPOCD Group. Long-term consequences of postoperative cognitive dysfunction. Anesthesiology. 2009;110(3):548-555.

3. Anwer HM, Swelem SE, el-Sheshai A, Moustafa AA. Postoperative cognitive dysfunction in adult and elderly patients--general anesthesia vs subarachnoid or epidural analgesia. Middle East J Anaesthesiol. 2006;18(6):1123-1138.

4. Hole A, Terjesen T, Breivik H. Epidural versus general anaesthesia for total hip arthroplasty in elderly patients. Acta Anaesthesiol Scand. 1980;24(4):279-287. 
5. Jones MJ, Piggott SE, Vaughan RS, et al. Cognitive and functional competence after anaesthesia in patients aged over 60: controlled trial of general and regional anaesthesia for elective hip or knee replacement. BMJ. 1990;300(6741):1683-1687.

6. Karhunen U, Jönn G. A comparison of memory function following local and general anaesthesia for extraction of senile cataract. Acta Anaesthesiol Scand. 1982;26(4):291-296.

7. Mandal S, Basu M, Kirtania J, et al. Impact of general versus epidural anesthesia on early post-operative cognitive dysfunction following hip and knee surgery. J Emerg Trauma Shock. 2011;4(1):23-28.

8. Davis N, Lee M, Lin AY, et al. Postoperative cognitive function following general versus regional anesthesia: a systematic review. J Neurosurg Anesthesiol. 2014;26(4):369-376.

9. Werdehausen R, Braun S, Essmann F, et al. Lidocaine induces apoptosis via the mitochondrial pathway independently of death receptor signaling. Anesthesiology. 2007;107(1):136-143.

10. Johnson ME, Uhl CB, Spittler KH, Wang H, Gores GJ. Mitochondrial injury and caspase activation by the local anesthetic lidocaine. Anesthesiology. 2004;101(5):1184-1194.

11. Takenami T, Yagishita S, Murase S, et al. Neurotoxicity of intrathecally administered bupivacaine involves the posterior roots/posterior white matter and is milder than lidocaine in rats. Reg Anesth Pain Med. 2005;30(5):464-472.

12. Sakura S, Kirihara Y, Muguruma T, Kishimoto T, Saito Y. The comparative neurotoxicity of intrathecal lidocaine and bupivacaine in rats. Anesth Analg. 2005;101(2):541-547.

13. Lirk P, Haller I, Colvin HP, et al. In vitro, inhibition of mitogen-activated protein kinase pathways protects against bupivacaine- and ropivacaineinduced neurotoxicity. Anesth Analg. 2008;106(5):1456-1464.
14. Spaan PE, Raaijmakers JG, Jonker C. Early assessment of dementia: the contribution of different memory components. Neuropsychology. 2005;19(5):629-640.

15. Storm C. The semantic structure of animal terms: a developmental study. Int J Behav Dev. 1980;3(4):381-407.

16. Cehajic-Kapetanovic J, Bishop PN, Liyanage S, King T, Muldoon M, Wearne IM. A novel Ocular Anaesthetic Scoring System, OASS, tool to measure both motor and sensory function following local anaesthesia. Br J Ophthalmol. 2010;94(1):28-32.

17. Glossary. Spine. 2000;25:3200-3202.

18. Zakriya K, Sieber FE, Christmas C, Wenz JF, Franckowiak S. Brief postoperative delirium in hip fracture patients affects functional outcome at three months. Anesth Analg. 2004;98(6):1798-1802.

19. Newman MF, Grocott HP, Mathew JP; Neurologic Outcome Research Group and the Cardiothoracic Anaesthesia Research Endeavors (CARE) Investigators of the Duke Heart Center. Report of the substudy assessing the impact of neurocognitive function on quality of life 5 years after cardiac surgery. Stroke. 2001;32(12):2874-2881.

20. Ancelin ML, de Roquefeuil G, Ritchie K. [Anesthesia and postoperative cognitive dysfunction in the elderly: a review of clinical and epidemiological observations]. Rev Epidemiol Sante Publique. 2000;48(5):459-472.

21. Selwood A, Orrell M. Long term cognitive dysfunction in older people after non-cardiac surgery. Ouctomes from various studies differ, and no definite conclusion is possible. BMJ. 2004;328:120-121.
Local and Regional Anesthesia

\section{Publish your work in this journal}

Local and Regional Anesthesia is an international, peer-reviewed, open access journal publishing on the development, pharmacology, delivery and targeting and clinical use of local and regional anesthetics and analgesics. The journal is included in PubMed, and welcomes submitted papers covering original research, basic science, clinical studies,

\section{Dovepress}

reviews and evaluations, guidelines, expert opinion and commentary, case reports and extended reports. The manuscript management system is completely online and includes a very quick and fair peer-review system, which is all easy to use. Visit http://www.dovepress.com/ testimonials.php to read real quotes from published authors. 